\title{
rommhalina
}

(8)

\section{Poliúria e polidipsia}
Autor(es): $\quad$ Cardoso, Rita
Publicado por: Imprensa da Universidade de Coimbra
URL persistente: URI:http://hdl.handle.net/10316.2/43137
DOI: DOI:https://doi.org/10.14195/978-989-26-1300-0_36

Accessed : $\quad$ 26-Apr-2023 08:40:20

A navegação consulta e descarregamento dos títulos inseridos nas Bibliotecas Digitais UC Digitalis, UC Pombalina e UC Impactum, pressupõem a aceitação plena e sem reservas dos Termos e Condições de Uso destas Bibliotecas Digitais, disponíveis em https://digitalis.uc.pt/pt-pt/termos.

Conforme exposto nos referidos Termos e Condições de Uso, o descarregamento de títulos de acesso restrito requer uma licença válida de autorização devendo o utilizador aceder ao(s) documento(s) a partir de um endereço de IP da instituição detentora da supramencionada licença.

Ao utilizador é apenas permitido o descarregamento para uso pessoal, pelo que o emprego do(s) título(s) descarregado(s) para outro fim, designadamente comercial, carece de autorização do respetivo autor ou editor da obra.

Na medida em que todas as obras da UC Digitalis se encontram protegidas pelo Código do Direito de Autor e Direitos Conexos e demais legislação aplicável, toda a cópia, parcial ou total, deste documento, nos casos em que é legalmente admitida, deverá conter ou fazer-se acompanhar por este aviso. 


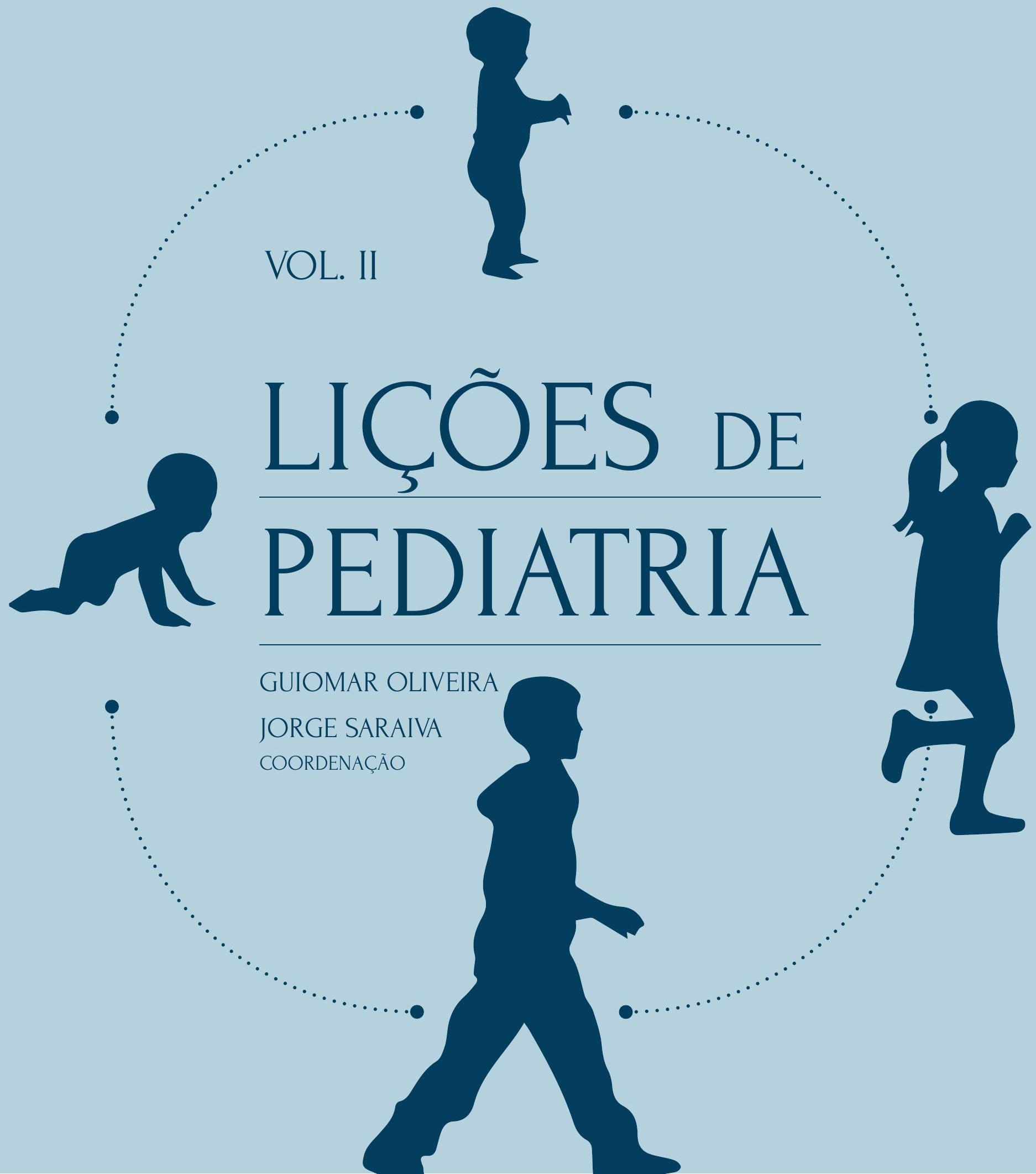


Capítulo 36.

Poliúria e polidipsia
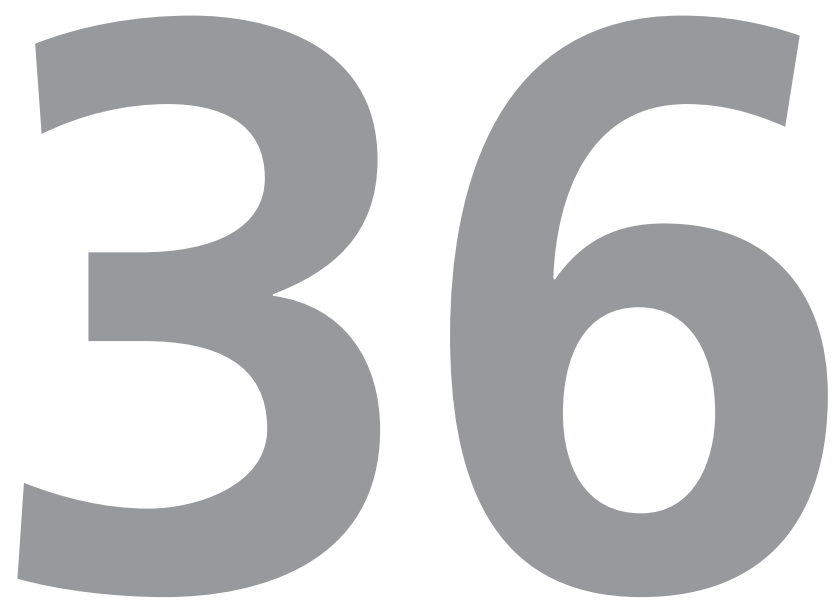

\section{Rita Cardoso}




\subsection{CONTEXTO}

A poliúria na criança define-se por um débito urinário superior a 2 litros/m2/dia (> $5 \mathrm{ml} / \mathrm{Kg} / \mathrm{h}$ ). Deve ser diferenciada de outras queixas mais habituais como a polaquiúria ou nictúria, em que o volume total de urina não está aumentado, no entanto a nictúria pode ser o primeiro sinal de poliúria uma vez que durante a noite há restrição de ingestão de líquidos. Está habitualmente associada a polidipsia com aumento da ingestão de água (> 100 ml/Kg/dia; 6 litros/dia).

\subsection{DESCRIÇÃO DO TEMA}

\subsubsection{Regulação da homeostasia de água e osmolaridade}

A hormona antidiurética (HAD) também conhecida como arginina vasopressina é sintetizada no núcleo supraóptico e paraventricular do hipotálamo anterior e vai através dos axónios dos neurónios, ser armazenada sob a forma de grânulos na hipófise posterior, entrando na circulação sistémica através do seio cavernoso e da veia cava superior. A HAD, considerada a principal hormona envolvida na regulação da homeostasia da água e osmolaridade, tem como primordial função a diminuição do débito urinário aumentando a reabsorção de água livre no túbulo contornado distal e ducto coletor dos nefrónios através da ligação aos recetores V2. Promove também a reabsorção de cloreto de sódio a nível da ansa de Henle. Assim, contribui para o aumento da osmolaridade urinária diminuindo a osmolaridade plasmática. $\mathrm{O}$ seu efeito é rapidamente reversível apresentando uma semivida de cinco a 15 minutos. Através da ligação aos recetores V1 no músculo liso, provoca contração do trato gastrointestinal e vasoconstrição (por isso a designação de vasopressina).

Quando os osmorecetores hipotalâmicos detetam aumento da osmolaridade sérica (basta aumento de $1 \%$ relativamente ao normal) a HAD é secretada. O limiar em termos de osmolaridade para esta secreção é de 280 a $290 \mathrm{mOsm} / \mathrm{litro}(\mathrm{L})$. Pelo contrário a diminuição da osmolaridade sérica em $1 \%$ leva à sua supressão permitindo a diurese de água.

A diminuição da volémia ou a diminuição da pressão arterial em 10 a 20\% determina também a secreção de $H A D$, sendo este estimulo mais potente do que a osmolaridade. A náusea é outro dos estímulos para a sua produção.

No entanto a HAD não consegue diminuir a diurese abaixo do limiar necessário para a excreção da carga de solutos que têm que ser eliminados pelo rim, sendo necessários outros mecanismos.

Outra forma de combater a perda de água é a sede, que é regulada por osmorecetores hipotalâmicos menos sensíveis que os da HAD. O limiar osmótico para despertar sede é 5 a $10 \mathrm{mOsm} / \mathrm{L}$ superior ao limiar para a secreção de HAD.

\subsubsection{Causas}

\subsubsection{Diurese Osmótica}

\section{Diabetes mellitus tipo 1 e tipo 2}

A diabetes mellitus (DM) é a causa mais frequente de poliúria e polidipsia.

É uma patologia do metabolismo dos hidratos de carbono e dos lípidos. A DM tipo 1 resulta 
de um défice absoluto na produção de insulina por destruição das células beta pancreáticas e na tipo 2, inicialmente há resistência à ação da insulina e posteriormente há um défice relativo da sua produção. Apesar da incidência da diabetes tipo 2 ter vindo a aumentar nas últimas décadas, associada ao aumento da obesidade nas crianças e jovens, a diabetes tipo 1 continua a ser a causa mais frequente de diabetes mellitus em idade pediátrica.

A incidência da DM tipo 1 tem vindo também a aumentar principalmente nas crianças com idade inferior a cinco anos. A patogénese combina fatores de risco genéticos (complexo major de histocompatibilidade do cromossoma 6) a fatores ambientais que despoletam o processo autoimune de destruição de células $\beta$. Os auto anticorpos podem estar presentes anos antes da manifestação da doença.

O défice de produção de insulina está associado a hiperglicémia com incapacidade da glicose entrar nas células e aumento da excreção renal de glicose (glicosúria) com diurese osmótica associada. Surge então a sintomatologia característica conhecida como os três Ps, poliúria, polidipsia e polifagia. A incapacidade de utilização da glicose leva a utilização dos lípidos como fonte de energia alternativa resultando na produção de corpos cetónicos, que por sua vez pode resultar em cetoacidose. À data do diagnóstico a maioria dos doentes apresenta sinais de desidratação e podem apresentar acidose metabólica (hiperventilação) e um hálito cetónico típico (cheiro a maçã).

Perante a sintomatologia típica o diagnóstico é feito associando uma glicémia em jejum $\geq$ $126 \mathrm{mg} / \mathrm{dl}$ ou em qualquer altura do dia $\geq 200$ mg/dl com ou sem cetonémia e cetonúria. Pode também haver aumento da hemoglobina A1C ( $\mathrm{HbA} 1 \mathrm{C} \geq 6,5 \%)$.

O melhor teste de rastreio consiste na realização de uma glicémia capilar e de um teste rápido de urina para pesquisa de glicosúria e cetonúria. Sempre que possível deve ser também, ou em alternativa à cetonúria, pesquisada a cetonémia que é detetada mais precocemente que a cetonúria e normaliza antes, sendo útil na monitorização do tratamento. Na diabetes tipo 1 encontram-se presentes os auto anticorpos (anti insulina, anti descarboxílase do ácido glutâmico, anti ilhéus de Langherans).

As crianças com suspeita deste diagnóstico devem ser referenciadas de imediato a um serviço de urgência de Pediatria pelo risco de vida associado.

\subsubsection{Diabetes insípida}

Excreção de um volume elevado urina diluída. Que se caraterizada por densidade urinária <1.010 ou osmolaridade urinária <300 mOsm/ kg; osmolaridade plasmática> 290 mOsm/kg com osmolaridade urinária $<300 \mathrm{mOsm} / \mathrm{kg}$.

A diabetes insípida (DI) tem uma incidência de 3/100.000 na população em geral com predominância discreta no género masculino (60\%).

\section{Diabetes insípida central}

Também designada como neuro-hipofisária ou neurogénica está associada a um défice de secreção da hormona antidiurética. Pode estar associada a malformações cerebrais congénitas ( 5 a $10 \%$ ), trauma, tumores e cirurgia hipofisária (50\% das causas adquiridas), infeções do sistema nervoso central, histiocitose de células de Langerhans (10\% das causas adquiridas), encefalopatia 
hipóxico-isquémica, destruição autoimune das células produtoras de HAD ou pode ser idiopática (10 a $20 \%$ ). Raramente, em menos de $10 \%$, existem casos familiares (formas autossómicas dominantes; síndrome DIDMOAD-diabetes insípida, diabetes mellitus, atrofia ótica e surdez-deafness), inferior a $10 \%$. Os eletrólitos podem ser normais já que a criança com acesso e capacidade para ingerir água não tem hipernatrémia. O início da poliúria é rápido. O volume de urina é elevado, está presente nictúria e há preferência por ingestão de água gelada. Nestes casos há resposta à desmopressina (fármaco análogo da vasopressina-HAD).

\section{Diabetes insípida nefrogénica}

Ocorre por diminuição da capacidade de concentração renal por resistência à ação da HAD. Pode ser adquirida (mais comum e menos grave) ou familiar.

As formas adquiridas podem estar associadas a distúrbios metabólicos (hipercalcémia, hipocaliémia), doença renal crónica, uropatia pós-obstrutiva e fármacos (lítio, rifampicina).

As formas familiares estão relacionadas com mutação do recetor V2 da vasopressina na forma ligada ao cromossoma X (manifestam-se habitualmente no primeiro ano de vida) ou da aquaporina 2 na forma de hereditariedade autossómica dominante (mais tardia).

O diagnóstico implica a demonstração da incapacidade de concentração renal na presença de um doseamento de HAD normal e não respondem à introdução da desmopressina.

\section{Polidipsia primária}

Também designada como polidipsia psicogénica. Ocorre mais em adolescentes e tem por base um aumento na ingesta de água com supressão da HAD e produção de quantidade de urina equivalente à ingesta de água. A poliúria melhora durante a noite com diminuição do aporte de água. Pode ocorrer em doentes com patologia psicológica/psiquiátrica ou com lesões hipotalâmicas que afetem o centro da sede. Uma osmolaridade plasmática> 295 mOsm/kg e sódio sérico> $143 \mathrm{mEq} / \mathrm{L}$ com ingestão de água ad libitum exclui esta etiologia.

\subsubsection{Diagnóstico e diagnóstico diferencial}

Clínica: irritabilidade; má progressão ponderal; anorexia; obstipação; febre intermitente; cefaleias; desidratação grave nas doenças correntes banais, ambiente quente ou na ausência de ingestão de água; dilatação de ureteres e bexiga; convulsões e coma.

Nos recém-nascidos e lactentes é difícil detetar poliúria e polidipsia, pode ocorrer irritabilidade mantida, vómitos, fraldas muito molhadas, necessidade muito frequente de mamar, pele seca, extremidades frias e insuficiente aumento ponderal ou mesmo convulsões e choque hipovolémico.

O diagnóstico dos tipos parciais de diabetes insípida pode ser difícil e as formas familiares podem manifestar-se de modo progressivo com agravamento da poliúria e polidipsia nos primeiros seis anos de vida.

\section{Anamnese - questões importantes a colocar:}

Há aumento do volume de urina ou aumento do número de micções?

Há polidipsia ou formas estranhas de saciar a sede? 
A necessidade de beber e urinar interfere nas atividades diárias normais?

Há nictúria ou enurese inapropriadas para a idade?

Interrompe o sono para beber?

Qual a bebida preferida?

Há perda de peso? Ou alteração do crescimento?

Idade de início sintomas?

História familiar de diabetes mellitus ou insípida?

Antecedentes de neurocirurgia, traumatismo crânio-encefálico, meningite, doença psiquiátrica ou patologia renal?

Toma de fármacos como diuréticos, lítio, analgésicos, vitamina $D$, cálcio ou fármacos nefrotóxicos?

Tem infeções recorrentes?

\section{Exame objetivo}

Deve ser completo devendo incluir sempre a avaliação de peso e estado nutricional e os sinais de desidratação. Avaliar sinais de puberdade precoce ou alterações ao exame neurológico (ponderar fundoscopia).

\section{Investigação laboratorial}

Muito importante quantificar o volume diário de urina e a ingesta hídrica.

i) Avaliação simultânea do sódio ( $\mathrm{Na}$ ) sérico e da densidade urinária na primeira urina da manhã constituem a forma de rastreio mais apropriada para a diabetes insípida (Na sérico> $143 \mathrm{mEq} / \mathrm{L}$ na presença de densidade urinária baixa e na ausência de aumento da ingesta de água é muito sugestivo de diabetes insípida; Na sérico> $145 \mathrm{mmol} / \mathrm{L}$ ou osmolaridade sérica> $300 \mathrm{mOsm} / \mathrm{Kg}$ com osmolaridade urinária $<600 \mathrm{mOsm} / \mathrm{Kg}$ confirma o diagnóstico de diabetes insípida - não se deve fazer prova de restrição hídrica nestes casos).

ii) Colheita de urina de 24 horas (avaliar volume total urina), avaliação do sódio sérico, osmolaridade sérica; osmolaridade e densidade urinárias.

As osmolaridades plasmática e urinária, são importantes para decidir a investigação posterior. Se a relação entre a osmolaridade urinária e plasmática for inferior a 0,7: deve ser efetuada uma prova de restrição hídrica para diferenciar polidipsia primária de diabetes insípida. Se for superior a 1.5 considerar diurese osmótica. A interpretação dos parâmetros analíticos em casos de poliúria e polidipsia sem glicosúria encontra-se resumida no quadro 1.

iii) Prova de restrição hídrica - doseamento de HAD sérica, osmolaridade plasmática e urinárias seriadas durante quatro a seis horas de restrição de ingesta hídrica.

Permite avaliar se em condições de restrição da ingestão hídrica a manutenção da poliúria determina que o sódio sérico e a osmolaridade plasmática subam para valores patológicos.

Permite a diferenciação entre diabetes insípida central e nefrogénica.

Esta prova está a cargo de especialistas desta área, pelos riscos que acarreta. 


\begin{tabular}{|l|l|l|l|l|l|}
\hline Diagnóstico & $\begin{array}{l}\text { Volume diário } \\
\text { urina }(\mathrm{L})\end{array}$ & $\begin{array}{l}\text { Na sérico } \\
(\mathrm{mmol} / \mathrm{L})\end{array}$ & $\begin{array}{l}\text { Osm sérica } \\
(\mathrm{mOsm} / \mathrm{L})\end{array}$ & $\begin{array}{l}\text { Densidade } \\
\text { urinária }\end{array}$ & $\begin{array}{l}\text { Osm } \\
\text { urinária }\end{array}$ \\
\hline Valores normais & $0,5-1^{*}$ & $135-145$ & 280 & $>1.010$ & $50-1400$ \\
\hline Diabetes insipida central & $4-10$ & $>145$ & $>300$ & $<1.010$ & $<200$ \\
\hline Diabetes insipida nefrogénica & $4-10$ & 170 & $>300$ & $<1.005$ & $<300$ \\
\hline Polidipsia primária & $2,5-20$ & 140 & $>280$ & $<1.020$ & $<200$ \\
\hline $\begin{array}{l}\text { *normal para a idade: RN- } \\
\text { 0,05-0,3L; } 1^{\circ} \text { ano vida } \\
\begin{array}{l}\text { a,4-0,5 L; criança 0,5-1L; } \\
\text { adolescentes 0,7-1,4L. }\end{array}\end{array}$ & & & & & \\
\hline
\end{tabular}

Quadro 1. Interpretação dos parâmetros analíticos em quadro de poliúria, polidipsia sem glicosúria.

Os resultados podem ser difíceis de interpretar nos doentes com diabetes insípida neurogénica parcial, resultante da secreção subnormal de HAD ou nos doentes com diabetes insípida nefrogénica parcial resultante da resposta parcial do rim a concentrações normais de HAD.

iv) Avaliação de outras hormonas hipofisárias (hipófise anterior)

v) Ressonância magnética crânio-encefálica para esclarecimento da etiologia da diabetes insípida, exclusão de tumores ou espessamento da haste hipofisária; é muito característico não se observar a imagem brilhante típica da neuro-hipófise (pode ser normal na fase inicial da diabetes insípida e a imagem do tumor só surgir anos mais tarde).

\subsubsection{Tratamento}

\section{Diabetes mellitus}

Correção da cetoacidose ( $\mathrm{pH}<7,3$ ou bicarbonato de sódio $<1,5 \mathrm{mmol} / \mathrm{L}$ ) com glicémia $>$ 200 mg/dl (é uma emergência com risco de vida).
Correção da desidratação e desequilíbrios eletrolíticos associados.

Insulinoterapia (introduzir apenas em serviço de urgência com pediatria) - em perfusão continua após um período inicial de hidratação com soro fisiológico e posteriormente com análogos de insulina de ação lenta administrados uma ou duas vezes por dia para mimetizar a insulina basal e análogo de insulina de ação rápida de acordo com os hidratos de carbono ingeridos às refeições e correção da hiperglicemia - esquema basal bólus (método mais fisiológico).

Podem ser utilizados sistemas de perfusão subcutânea contínua de insulina que permitem a sua administração através de um cateter subcutâneo, com possibilidade de ajustar de forma mais precisa as doses de insulina às necessidades de cada criança, permitindo melhor controlo metabólico e melhor qualidade de vida para as crianças e suas famílias.

Deve ser feita contagem dos hidratos de carbono das refeições e administrada a insulina de acordo com a ingesta, sempre antes da refeição, 
devendo fazer uma alimentação saudável como qualquer criança da mesma idade, mas com liberdade alimentar.

Os pais e as crianças devem receber educação terapêutica adequada e permanente para promover o melhor controlo metabólico que irá impedir ou atrasar as complicações que podem estar associadas à diabetes mellitus (agudas-hipoglicémia ou cetoacidose; crónicas-retinopatia, nefropatia, neuropatia e patologia cardiovascular). O rigor terapêutico é particularmente importante nestas idades pelo tempo de evolução natural que a doença vai ter.

Os adolescentes constituem um grupo de difícil abordagem pelas alterações hormonais existentes nesta fase associadas a insulinorresistência e maior dificuldade no controlo das glicémias e pelos comportamentos de fraca adesão à terapêutica.

\section{Diabetes insípida central}

Desmopressina: análoga da vasopressina, administrada por via oral a cada 8 a 12 horas, início de ação em 15 a 30 minutos, em alternativa pode ser usada a via intranasal ou endovenosa.

\section{Diabetes insípida nefrogénica}

Acesso livre à água.

Correção dos distúrbios metabólicos, suspensão de fármacos que estejam a usar.

Nas formas familiares são recomendados diuréticos tiazidicos, amiloride e indometacina e efetuada restrição de sódio na dieta. Estes casos se forem diagnosticados precocemente, com tratamento adequado podem ter desenvolvimento e esperança de vida normais apesar de apresentarem má progressão ponderal e baixa estatura pela má nutrição associada à polidipsia mantida.
Conclusão, em caso de clínica de poliúria e polidipsia:

- Confirmar poliúria (medir densidade urinária e pesar).

- Pode ser causada por diurese de água (osmolaridade urinária < plasmática) ou osmótica (osmolaridade urinária $\geq$ plasmática).

- Excluir infeção urinária e diabetes meIlitus (glicémia, cetonémia, glicosúria e cetonúria).

- Fazer avaliação da ureia, creatinina, gasometria, cálcio, sódio sérico, osmolaridade sérica, osmolaridade urinária. Ponderar prova de restrição hídrica.

\subsection{FACTOS A RETER}

Não deixar de suspeitar de diabetes mellitus perante uma criança com poliúria e polidipsia, devendo ser avaliadas: glicémia e glicosúria, cetonúria/cetonémia.

\section{Não deve ser administrada insulina fora} da urgência pediátrica (risco de edema cerebral). Deve ser iniciada de imediato hidratação endovenosa com soro fisiológico.

A diabetes insípida apesar de rara é uma causa importante de poliúria na criança.

O ionograma normal não exclui o diagnóstico de diabetes insípida.

É fundamental saber diagnosticar diabetes mellitus e diabetes insípida e referenciar de imediato a um serviço de Pediatria.

A investigação e abordagem da diabetes mellitus e insípida devem ficar a cargo de especialistas nas áreas de endocrinologia/nefrologia pediátrica. 